\title{
A Game Analysis on Information Sharing of Military Procurement and Logistics Standardization
}

\author{
Darong Ling ${ }^{1}$, Fei Zhang ${ }^{1}$, Ziyi Wang ${ }^{1}$ and Yukun $\mathrm{Li}^{1}$ \\ ${ }^{1}$ Military Economics Academy, Wuhan, China
}

\begin{abstract}
Military procurement and logistics standardization is the base of the efficient and reasonable operation of modern military procurement \&logistics. It's significant to study logistics standardization and the standardization of logistics information management. This paper constructs a game model which aims at comparing costs and benefits on condition of absolute sharing, partial sharing or not sharing information based on the different information sharing rate and logistics institutes' expectation, furthermore, it discusses how to build a relationship of mutual trust, in order to make the logistics institutes develop activeness to fasten the pace of logistics standardization and the standardization of logistics information management.
\end{abstract}

With the continuous development of military procurement \& logistics standardization construction, military procurement \& logistics standardization is seen as the foundation of the modern military procurement \& logistics, at logistics information flow has become the key logistics activities, at the same time, more attention should be paid to logistics standardization research, and exerting efforts to expand standardized data exchange and application between logistics operation organizations, speeding up the transformation of military procurement \& logistics information management into scientific, standardized in order to improve the efficiency of the military procurement \& logistics and promote the construction of military procurement \& logistics standardization, which is of great significance to improve the efficiency of military procurement $\&$ logistics support and efficiency.

\section{Introduction}

Logistics standardization and normalization could be seen as the foundation of the realization of logistics rationalization and efficiency, also, the standardization of logistics information management is viewed as a watershed in modern military procurement $\&$ logistics and traditional military procurement \& logistics, unified information data exchange and sharing is very important for every member in military procurement \& logistics system. However, in the process of logistics standardization, because of having no specific standard or some standards has not got recognition and promotion, what is more, some institutional barriers of information resources management, and some related departments care about their own interests, which concerned about their logistics information becomes public would make them lose their own advantages in the field of information possession. Consequently, they have no initiative to share logistics information, which result out slowly information communication and inefficiencies in logistics operation.

Information exchange and sharing between logistics nodes and standardization organizations is a process of mutual benefit. It can realize the bilateral benefit and facilitate the military procurement \& logistics system coordinating and efficient operation, otherwise, military procurement \& logistics system will be blocked. Therefore, it is the key to improve the overall efficiency and benefit of military procurement \& logistics that dedicated to information sharing and standardization of information management.

Taking military procurement \& logistics information flow as the research object, exploring the motivation that push on the standardization of military procurement \& logistics information management, and promoting the standardization of military procurement \& logistics management information construction, how to participate in both sides achieve this kind of information sharing and increase their benefit through the game, and improve the overall efficiency should be understood, thus in a higher level and deeper extent promoting the military procurement \& logistics standardization construction. In view of this, cooperation game model is constructed to analyze the evolution mechanism of this kind of a win-win relationship.

\section{The establishment of the model}

Generally speaking, in the advance of military procurement \& logistics standardization should be led by the military procurement \& logistics standardization committee which working with the military procurement 
\& logistics operation organizations and logistics nodes that usually more than one independent agency or organization. In order to simplify the research, here only consider the one-to-one game mode.

\subsection{Bilateral earnings analysis of the payoff function}

The effective exchange of information between the standardization committee and military procurement \& logistics operation organizations would make the military procurement \& logistics operation smoothly. From the perspective of standardization committee, on the one hand, it can get information feedback from military procurement \& logistics organizations to get firsthand material to set standards, promote military procurement \& logistics information standardization and management standardization easily, and improve the performance. On the other hand, bilateral accelerating construction progress together that can save the special funds of military procurement \& logistics standardization construction. For military procurement \& logistics operation organizations, implement the logistics standardization could reduce logistics operation cost, improve efficiency, and improve business performance. As a result, this paper considers this behavior as a specific payoff function of decision-making. Since the decision-making and strategy game with similar characteristics, thus assumed that the military procurement \& logistics standardization committee's benefits paid function is $\left(\pi_{A}^{i}\right)$,the military procurement $\&$ logistics operation organizations' benefits paid function is $\left(\pi_{B}^{i}\right)$.

\subsection{Construction of basic model}

Game bilateral are rational and willing to pursuit of self-interest maximization and risk-averse. In military procurement \& logistics operation process, regional military procurement \& logistics standardization organizations and institutions may retain a lot of important exclusive information, which result out the game is carried under the condition of asymmetric information. If logistics standardization committee obtain more information, but do not share it with military procurement $\&$ logistics operation organizations, what is more, the committee thinks it would be the dominant in the military procurement $\&$ logistics standardization and information management standardization; on the other hand, the military procurement \& logistics operation organizations also could retain their information and do not involved in information sharing; otherwise, both sides share information with each other to realize win-win situation, improve business efficiency and reduce cost. The specific game situation and the basic model is shown in table 1:

military procurement \& logistics standardization committee
Table 1. Statics game model of military procurement $\&$ logistics information sharing

\begin{tabular}{l|l|l|c|}
$\begin{array}{c}\text { military } \\
\text { procurement and } \\
\text { logistics operation } \\
\text { organizations }\end{array}$ & sharing & sharing & not sharing \\
\cline { 2 - 4 } & not sharing & $c, b$ & $b, c$ \\
\cline { 2 - 4 } & & & \\
& &
\end{tabular}

Assuming that bilateral side choose information sharing strategy, the earnings is respectively $a$ and $a$; unilaterally choosing information sharing strategy, sharing the benefits for $b$, information alone is protected well income to $c$; Bilateral choice alone retain strategy, revenue $d$ and $d$ respectively, what is more, for general, $c>a>d>b>0$.

\section{Static game under information sharing}

It assumes that logistics information sharing rate of military procurement \& logistics standardization organization is $\rho(0<\rho<1)$ in reality, while, logistics information sharing rate of military procurement \& logistics organization is $\psi(0<\psi<1)$, then, the game model is as follows:

military procurement \& logistics standardization organization

Table 2. Information sharing game model of military procurement \& logistics

\begin{tabular}{|c|c|c|}
\hline & $\begin{array}{c}\text { sharing rate } \\
(\rho)\end{array}$ & $\begin{array}{c}\text { not sharing } \\
\text { rate }(1-\rho)\end{array}$ \\
\hline Sharing rate $(\psi)$ & $\psi a, \rho a$ & $\psi b, c-\rho c$ \\
\hline $\begin{array}{c}\text { not sharing rate } \\
(1-\psi)\end{array}$ & $c-\psi c, \rho b$ & $d-\psi d, d-\rho d$ \\
\hline
\end{tabular}

(1) Assuming that military procurement \& logistics standardization organization choose complete information sharing, logistics operation organization made the same decision as well, namely $\rho=1, \psi=1$, thus, it forms a static game model.

The specific process of a single stage game is shown in figure 1, which illustrates that the standardization organization adopts information sharing strategy, logistics operation organization would compare cost and gains( $c>$ a), and then selects information retaining strategy. On the other hand, if standardization organization selects information retaining strategy, logistics operation organization may yield profits $d(d>b)$ and select information retaining strategy. Consequently, logistics standardization organization and logistics operation organization would both choose information preserving strategy under those conditions, also, the benefits is $\mathrm{d}$ respectively, while the earnings $d<a$, therefore, both of them would eventually prefer the dominant strategy 
choice to share information and get profits a. According to the theory of Nash equilibrium, if the operation of military procurement $\&$ logistics is just only a one time static game, then the gains group $(a, a)$ would be seen as the Nash equilibrium. However, it is a long-term process of cooperative game that the logistics operation and information sharing for the standardization organization and operation organization as well, accordingly, this strategy choice is not proper for both in reality.

In table 2 , the military procurement \& logistics standardization committee and the logistics operation organizations yield profits are:

$$
\begin{aligned}
& \pi_{A}{ }^{1}=\mathrm{n} \rho a-\frac{\delta \rho \mathrm{a}}{1-\delta} \\
& \pi_{B}^{1}=n \psi a-\frac{\delta \psi a}{1-\delta}
\end{aligned}
$$

Then, the bilateral total revenue is:

$$
\pi_{\mathrm{t}}=\mathrm{n}(\rho+\psi) \mathrm{a}-\frac{\delta \mathrm{a}}{1-\delta}(\rho+\psi)
$$

Since, $\rho=1, \psi=1$, so ,

$$
\pi_{\mathrm{t} 1}=2 \mathrm{na}-\frac{2 \delta \mathrm{a}}{1-\delta}
$$

(2) Assuming that both of them share part of information, namely preserve some logistics information respectively, might as well set the possibility $\rho=0.5$, $\psi=0.5$, then the total revenue is:

$$
\pi_{\mathrm{t} 2}=\frac{1}{2}\left(2 \mathrm{na}-\frac{2 \delta \mathrm{a}}{1-\delta}\right)
$$

(3) Assuming that both of them don't share any information and preserve all the information by themselves, obviously, the possibility $\rho=0, \quad \psi=0$, the profits of military procurement $\&$ logistics standardization committee is as follows:

$$
\pi_{\mathrm{A}}^{3}=(1-\rho) c+(n-1)(1-\rho) d-\frac{\delta(1-\rho)}{1-\delta}(c+\delta d-\delta c)
$$

The earnings of logistics operation organization is:

$$
\pi_{\mathrm{B}}^{3}=(1-\psi) c+(n-1)(1-\psi) d-\frac{\delta(1-\psi)}{1-\delta}(c+\delta d-\delta c)
$$

The total earnings of bilateral organization is:

$$
\pi_{\mathrm{t} 3}=2 c-2(n-1) d-\frac{2 \delta}{1-\delta}(c+\delta d-\delta c)
$$

Through comprehensive comparison of the earnings in formulations above, it could conclude that: $\pi_{\mathrm{t} 1}=2 \pi_{\mathrm{t} 2}=\left(2 \mathrm{na}-\frac{2 \delta \mathrm{a}}{1-\delta}\right)$

Therefore, the total earnings gap of standardized information sharing and bilateral sharing with sharing rate is as follows:

$$
\begin{aligned}
\Delta \pi= & (\rho+\psi)\left[n \mathrm{a}+(n-1) d+(1-\delta) c-\frac{\delta \mathrm{a}}{1-\delta}\right] \\
& +2\left[\frac{\delta^{2} d}{1-\delta}-(1-\delta) c-(n-1) d\right]
\end{aligned}
$$

Calculating the integral derivation on parameters $(\rho+\psi)$, then,

$$
\frac{\partial \Delta \pi}{\partial(\rho+\psi)}=n \mathrm{a}+(n-1) d+(1-\delta) c-\frac{\delta \mathrm{a}}{1-\delta}
$$

Since $0<\delta<1$, thus, $\frac{\partial \Delta \pi}{\partial(\rho+\psi)}>0$, this formulation also indicates that along with the increase of $\rho+\psi$, the total earnings gap of complete standardized information sharing and bilateral information sharing with sharing rate becomes greater and bigger, which means the greater sharing ratio, the greater total earnings could get. Influencing by this game result, the military procurement \& logistics operation organizations are willing to cooperate and share information with military procurement \& logistics standardization committee, and constantly improve their additional value of information resources they owned, what is more, they would try to make the information become standardized and unified information management standard in order to accumulate its own operation basis and achieve the target of "win-win" in the military procurement \& logistics information sharing.

If bilateral organizations both adopt information preserving strategy completely, then, the total earnings gap between complete information sharing is:

$$
\begin{aligned}
\Delta \pi_{1}= & (1-\delta) \Delta \pi=2 \delta^{2}(d-c)+ \\
& 2 \delta[2 c+(n-1) d]-2[c+(n-d) d]
\end{aligned}
$$

Calculating the partial derivation on parameter $\delta$, then,

$$
\frac{d \Delta \pi_{1}}{d \delta}=4 \delta(c-d)-4 c-2(n-1) d<0
$$

Formulation above indicates that the total earnings gap between complete information sharing would become smaller and smaller under the condition of bilateral organizations both adopt information preserving strategy, namely the total earnings would decrease along with the incensement of preserving ratio. Accordingly, the operation cost is on the rise and the yield decreases when bilateral information don't share with each other, which means the logistics system lies in a state of mutual consumption and stalemate that both two sides are not willing to accept. Consequently, both of them hope to gaining more earnings from the process of information sharing, promoting the construction of logistics information standardization management process. In other words, the analysis result indicates that the relationship between logistics information sharing and logistics operating income as well as information management standardization is 'win-win' effect. 


\section{Repeated game and subjetive expectation analysis}

\subsection{The infinite repeated game of military procurement \& logistics information sharing}

Trigger strategy: assuming game is infinitely repeated, military procurement \& logistics standardization committee take the strategy of logistics information sharing, also, the logistics operation organizations adopt information sharing strategy in the early stage continued to stage $t$. If the earnings of bilateral organizations are (a, a) until stage $(t-1)$, then, they would continue to adopt the strategy of logistics information sharing, however, once they found that opposite side take preserving strategy alone, they would choose information retaining strategy without any doubt.

Assuming that logistics standardization committee takes trigger strategy, then, logistics operation organizations would also take the trigger strategy, if the coefficient of strategy selection costs and earnings is $\delta(0$ $<\delta<1$ ), the earnings of military procurement \& logistics operation organizations is:

If the military procurement \& logistics operation organizations do not take the trigger strategy, on the contrary, adopt retaining strategy in the first stage, thus,

$$
\begin{aligned}
\pi_{B}{ }^{t}= & \lim _{t \rightarrow \infty}\left[t \mathrm{a}-\left(\delta \mathrm{a}+\delta^{2} \mathrm{a}+\ldots+\delta^{t-1} \mathrm{a}+\delta^{t} \mathrm{a}\right)\right] \\
& =t \mathrm{a}-\frac{\delta \mathrm{a}}{1-\delta}
\end{aligned}
$$

they would receive a revenge and they have to adopt trigger strategy from the second phase. The earnings for the military procurement \& logistics operation organizations is:

$$
\begin{aligned}
& \pi_{B}{ }^{i}=\left(c-\delta c, d-\delta^{2} d, d-\delta^{3} d, \ldots, d-\delta^{n} d\right) \\
& \pi_{B}{ }^{n}=\lim _{n \rightarrow \infty}\left[c+(n-1) d-\delta c-\frac{\delta^{2} d}{1-\delta}\right]
\end{aligned}
$$

Thus, as long as the $\pi_{\mathrm{B}}{ }^{t}<\pi_{\mathrm{B}}{ }^{n}$, namely $\frac{c-\mathrm{a}}{c-d}<\delta<1$, trigger strategy is dominant strategy for military procurement \& logistics operation organizations, at the same time, trigger strategy is also dominant strategy for military procurement \& logistics standardization committee as well, accordingly, the trigger strategies construct a Nash equilibrium in the game of the military procurement \& logistics information sharing standardization. Pareto optimality policy (sharing, and sharing) constructs the equilibrium result of each stage, because of the unlimited times game this result would also be the final ending of long-standing game relation, which means the result and structure of any sub-game would be same no matter starting from any stage, therefore, the trigger strategy constructs a refining Nash equilibrium to the sub-game of infinite times repeated games.

Scripps and others have shown that, as long as the number of game is large enough, trigger strategy would also be positive to solve the "prisoner's dilemma" problem.
In specific, information sharing game is repeated for infinite times in military procurement \& logistics operation because of its long term running, what is more, military procurement $\&$ logistics operation organizations and military procurement \& logistics standardization committee both have patience and confidence to punish the opportunism behavior, thus, any earnings of short-term opportunism behavior appears insignificant, as well as both two sides have enthusiasm to build the reputation of cooperation willing. Through this way, military procurement $\&$ logistics military procurement $\&$ logistics operation organizations and military procurement \& logistics standardization committee both and military procurement \& logistics standardization committee could both avoid dilemma, what is more, the earnings from the cooperation would make both sides continue to cooperate and establish a mutual trust relationship in long-term cooperation, which could also further make them actively promote logistics information management standardization.

\subsection{Analysis based on of military procurement \& logistics operation organizations subjective expectations}

The discussion above suggests that military procurement \& logistics operation organizations and military procurement \& logistics standardization committee both have enthusiasm of sharing logistics information with other members. Consequently, assuming that military procurement \& logistics operation organizations pursuit sustainable long-term expectations on future earnings in addition to the earnings at this stage in the game process of standardization of logistics information sharing. Assuming that the earnings at this stage is $a$, its probability is $1-\mu, E$ for long-term expectations, its probability is $\mu \quad(0<\mu<1)$, therefore, the earnings is: $\pi=(1-\mu) \rho \mathrm{a}+\mu \rho E-(1-\mu) \rho \delta_{a}>\lambda \mathrm{a},(\lambda>1)$

then,

$E>\frac{\lambda-(1-\mu) \rho}{\rho \mu}+1-\delta$

Thus, $\mu$ is larger, the greater the chance of inequality could be established, which illustrates that military procurement $\&$ logistics operation organizations would be more motivated to participate in logistics information sharing based on the higher earnings expectations in the future. At the same time, the greater the value of $\rho$, which represents the standardized logistics information sharing, the more obvious the positive correlation between $\lambda$ and $E$, which also means that the higher enthusiasm of sharing logistics information.

\section{Conclusion}

The game analysis above shows that it is benefited to both military procurement \& logistics standardization committee and military procurement \& logistics 
organizations for sharing standardization information with each other. Military procurement \& logistics organizations have the higher expectations of future earnings and long-term cooperation, the higher enthusiasm of military procurement \& logistics information sharing. When this kind of enthusiasm into standardized information sharing actions, namely taking the sharing policy, contributing to the behavior of the information management standardization, and promoting the construction of logistics standardization more actively, their earnings and bilateral total revenue will be growing. Organizations for standardization play a key role of the implementation of the logistics information management of military procurement \& logistics organizations. The application and exchange of standardized information between the military procurement \& logistics organizations in order to promote the informatization construction of military procurement \& logistics and standardization of information management construction.

This paper insists that in the process of promoting the military procurement \& logistics information management standardization, standardization committee first should focus on strengthening of the standardization promotion, making more military procurement $\&$ logistics organizations more comprehensive understanding of military procurement \& logistics information management standardization. Second, it should establish a standardization of military procurement \& logistics information management incentive mechanism. Incentive in the process of information exchange and sharing of military procurement $\&$ logistics organizations can affect each logistics organization goals or needs, and affect the logistics organization action motivation. Third, it can also cultivate strategic partnership, and promote the continuous development of military procurement \& logistics information management standardization. This is the important foundation of improving the support efficiency and the important condition of civil-military integration support. So it can obtain a more competitive advantage, achieve their own goals and interests of the logistics organizations, and eliminate the differences of military procurement \& logistics management information system nodes, bring out economies of scale. Standardization committee is committed to improving the incentive of logistics information sharing, making each member of the military procurement $\&$ logistics system enhance the consciousness of sharing standardize information, cooperation and resources integration, which in order to achieve a win-win situation, and improve the support capability of military procurement $\&$ logistics .

\section{References}

1. Li ling, Wang xiang. Strategic thought in game theory. Shanghai Journal of Economics, 2010, vol.1, pp.35-41.

2. Schliekelman, P, and M. Slatkin. "A Game Analysis of Standardization of Aquatic Production Enterprises and Cold Chain Logistics Enterprises".LISS 2014, Springer Berlin Heidelberg, 2015, pp.3-7.

3. Sun, Shusheng, and G. Gui. "A Game Analysis of Standardization of Regional Modern Logistics." Logistics Technology. 2013, vol.64, pp. 4965-4972.

4. Wang, Cai Xia. "Analysis of the Value of Logistics Standardization to the Management and Decision-making of Logistics Corporation." Logistics Sci-Tech, 2009, vol.5, pp. 756-767.

5. Xiao, Rong $\mathrm{Na}$, and Q. W. Yin. "Mechanism for Promoting Logistics Information Sharing System Based on Game Theory." Transportation Standardization, 2012, pp.231-237.

6. Yuan, Qing. "Analysis on Fresh Agriculture Foods Logistics Mode in China and Cool Logistics Standardization Construction." Journal of Anhui Agricultural Sciences, 2013, vol.4, pp. 73-77.

7. Yang weilong, Lin jian. Study on the enterprise strategic management based on the game theory. Science of science and management, 2007, vol.8, pp.136-139.

8. Zhang, Yin Cong, and G. Y. Cui. "The Application Analysis of Logistics Standardization in Enterprise and the Model of Informational Share Game." Sci-Tech, 2009, vol.3, pp. 453-460.

9. Yang, Zou. "Analysis of China's Logistics Standardization Based on Economic Globalization." Storage Transportation \& Preservation of Commodities, 2008, pp.254-261.

10. Zheng mingchun. Research of baseding on the game for service overlay networks resources providing questions. Shangdong normal university, 2011, vol.8, pp.136-139.

11. Zhang, Ai Hua,. A Game Analysis of New Technical Equipment Procurement. The 19th International Conference on Industrial Engineering and Engineering Management. Springer Berlin Heidelberg, 2013, pp.703-708.

12. Zhang yincong, Gui gengyu. The application analysis of logistics standardization in enterprise and the model of information share game. Logistics science and technology, 2009, vol.5, pp.69-75. 